\title{
COMMENTARY:
}

\section{NEED OF A PROFESSIONAL CODE FOR}

\section{LIBRARIANS}

\section{G.M.P.GALLABA ${ }^{1}$}

BA (Hons), PGDL (Kelaniya), Attoney at Law.

\section{Abstract}

Ethical issues are common, at all levels of professional activity. Therefore professional associations lay down codes of conduct and ethics for maintaining members' behaviour up to expected levels.

Codes of conduct can succeed only if the profession as a whole feels responsible for its implementation. If the professionals as members of their profession fail to be responsible and do not take action against those who do not observe the code, the code becomes ineffective.

In accordance of these, Sri Lanka Library Association approved the Professional Code of Conduct and Ethics and published it in 1998. This paper explains the need for such a code and briefs on the code prepared for LIS professionals in the country a decade ago.

Keywords: Ethics, Professional ethics, Code of conduct, Library profession.

\footnotetext{
. Senior Assistant Librarian, University of Sri Jayewardenepura (pbgallaba@gmail.com).
} 


\section{Introduction}

\subsection{Ethics}

The word 'ethics' has originated from the Greek word 'ethos' meant for character, norms, morals and ideals prevailing in a group, society. There are distinctive attitudes pervading the culture of a group of persons, with adherence to certain values. It includes a definite tradition, and sharing in customs and experiences. Contemporary ethics strive to preserve what is essential in the older traditions and modifies others according to changes in the perception of the society (Francis, 2004).

Mintz (1992) states that ethics may be referred to as some standardised forms of conduct or behaviour of individuals understood and accepted in a particular field of activity. It may refer to a system or code of conduct based on moral duties and obligations that indicate how we should behave. It deals with the ability to distinguish right from wrong and the commitment to do what is right.

Bhatia (2004) describes Ethics as a mass of moral principles or sets of values about what conduct ought to be. They give an idea what is right or wrong, true or false, fair or unfair, just or unjust, proper or improper, e.g. honesty, obedience, equality, fairness etc. and respect and then doing the right thing.

The concept 'ethics' is pluralistic. Individuals disagree among themselves about what is right and what is wrong, and even when they agree it can be for different reasons. In some societies this disagreement is regarded as normal and it does not violate the rights of others. In some traditional societies there is greater agreement on ethics and social pressure to act in certain ways rather than others. In such societies culture and religion play a dominant role in determining ethical behaviour (Williams, 2005).

Ethical principles are dictated by the society and underline broad social policies. These principles when known, understood and accepted, generally determine the propriety of professional activities. 


\subsection{What is a profession?}

There is no universally accepted definition for the term 'profession'. People engage themselves in various pursuits. Politicians, farmers, industrialists, housewives, shopkeepers, bus drivers, craftsmen, carpenters, teachers, librarians, accountants, doctors, lawyers etc. all are engaged in special tasks during their day-today lives. But all of them are not professionals.

Professionalism refers to the conduct, aims, or qualities which characterise or make a profession or professional. Qualities of professionals are competence, objectivity and integrity.

Amarasinghe (1993) lists some features of professionals which helps us identify who professionals are.

1. Identifiable by reference to some register or record.

2. Recognised as having a special skill and learning in some field of activity in which the public needs protection against incompetence the standards of skill learning being prescribed by the profession itself.

3. Holding themselves out as being willing to serve the public.

4. Voluntarily submitting themselves to standards of ethical conduct beyond those required from the ordinary citizen by law.

5. Undertaking to accept personal responsibility to those whom they serve for their actions and to their profession for maintaining public confidence.

For example in Sri Lanka, the profession of Attorney at Law is regulated by the Constitution, and other laws approved by the Parliament. This includes sections 40, 41, 42, 43 and 44 of the Judicature Act No.2 of 1978 (rules regulating the admission, enrolment, suspension and removal of members of the legal profession), and the rules of conduct and etiquette and the rules pertaining to attire for such persons made in terms of Article 136(1) (g) and (h) of the Constitution. 
The members admitted to the legal profession and who are not disbarred are identifiable by referencing to the register maintained by the Supreme Court (Extraordinary Gazette No.9/10 of Nov.08, 1978).

\subsection{Professional ethics}

Professional ethics is the group of standards relating to the activities of professionals. It has come to be considered since the birth of the social responsibility of profession.

Every profession should have an ethical code. The code verbalises the ethics. Such a code fosters and guarantees ethics. It assures the members of the profession and the public a standard of professional relationships. The ethical code makes the ethos more concrete.

Ethical code is different from legislation. Often it does away with the need for legislation. The code serves as a guide. All members of the profession are expected to adhere to the code. There is need for ethical or righteous conduct in all our endeavours.

Kaptain and Klamer (1991) list 6 conditions for effective codes of ethics:

1. A valid motivation for its introduction. It should insist on important benefit for adopting and complying with the code.

2. Broad acceptance within the Association in the process of elaborating the code. The code should be discussed, checked and redefined before it is finally laid down.

3. Continuous feedback: Difficulties occur during the implementation of the code, and also norms on how to act in specific situation change. Living up to a code is not simply a matter of blindly applying rules; it is part of a process.

4. Verification and control. Any inconsistencies between rules and practice should be disclosed. One method of achieving this is peer discussions. 
5. Integration into a broad association philosophy on corporate services and responsibilities. The set of rules should be part of a wider ethical mission statement.

6. Compliance with codes needs enforcement both positive and negative

\section{Library Profession}

Many countries have introduced professional codes of conduct (PCC) for their librarian communities. International Federation of Library Associations (IFLA) lists a collection of 34 such professional guidelines for librarians and other library employees adopted by national libraries, or librarians associations, or implemented by government agencies (Professional Codes of Ethics for Librarians - IFLA).

\subsection{PCC implemented by foreign library associations}

For example, Italian Library Association (ILA) in its PCC highlights three main principles (ILA, 1997). It consists of duties towards the user, towards the profession and towards documents and information. It is interesting to see how much professionals should be devoted to clientele according to the first section of the document.

\subsubsection{ILA professional code of conduct - duties towards the user}

- The librarian guarantees the user access to publicly available information and to documents without any restriction that is not explicitly and previously stated in laws or regulations.

- The information supplied by the librarian shall be complete, objective and impartial, i.e., unconditioned by the librarian's personal viewpoints, ideas and values, neither by external political and economic bodies. 
- The librarian, in managing the library and its services for the public, shall not accept any conditioning as sex, ethnic group, nationality, social condition, religion or political opinions.

- The librarian shall reject and oppose any form of censorship of the documents gathered and organised and of the information supplied.

- The librarian guarantees the confidentiality of the user, of the information he requested or received and of the information sources used.

- In carrying out his professional duties, the librarian should not place himself in a position of conflict of interest and shall not use the information and resources available to him by virtue of his position for his personal interest.

- It is the duty of the librarian to promote, both individually and collectively, the efficiency and the independence of the library service as an instrument of democracy.

\subsection{Sri Lanka Library Association (SLLA)}

SLLA is the only professional association of the country representing all library professionals in Sri Lanka. Among objectives of the association, there is the responsibility of setting up professional standards.

The council of the Sri Lanka Library Association approved the Code of Professional Conduct and Ethics (CPCE) and published it in 1998. It states that Librarians - including Information scientists - are professionals. As members of a profession, librarians have a duty to:

1. Observe the highest standard of conduct and integrity.

2. Act honestly in performing professional services.

3. Carry out professional services in accordance with professional standards.

4. Refrain from any conduct which might bring discredit to the profession. 
Members of the association are required to observe the principles laid down in the CPCE as a condition of membership.

The principles of conduct have been embodied in the following broad categories:

1. Responsibility to the employing organization, Community and users.

2. Responsibility to the profession and practices.

3. Responsibility to the professional body. (SLLA, 1998)

In addition, SLLA Act, No.7 of 2004 gives power to SLLA for the following.

- to establish, maintain and promote library documentation and information services in Sri Lanka and to set up professional standards for such services.

- $\quad$ to safeguard, protect and promote the rights, privileges, and status.

- to introduce a CPCE for members and monitor the implementation of such code.

According to the act, powers have been given to SLLA to constitute disciplinary committees and standing committees as the council deems necessary. It also allows making recommendations to the corporation with regard to additions, alterations and amendments to the rules and regulations and to the CPCE. (SLLA Act, No.7 of 2004).

Most importantly, codes and values should be developed having a continuing dialogue alongside. The code should be updated periodically as and when the necessity arises. SLLA has powers by the Act to take necessary action to disenroll any member who in its opinion has been guilty of professional misconduct (SLLA Act, No.7 of 2004.) 
Harrison Perera, then President of SLLA, forwarding the code of conduct and ethics in 1998 mentioned that he hopes that the code will promote the standing of LIS profession and will provide a clear massage to the public about the work involved with and help to raise awareness of what it means to be a library and information professional (SLLA, 1998).

\section{Conclusion}

Ethics means a set of moral principles - a code of conduct. It deals with the right conduct. It helps in distinction between what is considered right or wrong at a given time, in a given culture, with the moral consequences of the action. In any social set-up, the members of a group tend to adopt a set of rules of behaviour for the establishment of good order. Such rules may or may not be codified, but so long as they have the acceptance of the members of the group, they tend to be observed to achieve certain desired objectives.

\section{References}

Amarasinghe, A. R. B. (1993). Professional ethics and responsibilities of lawyers. Colombo: Lake House Investments.

Bhatia, S. K. (2009). Business ethics and management values. New Delhi: Deep \& Deep Publications.

Francis, C. M. (2004). Medical ethics. New Delhi: Jaypee Brothers.

Government of Sri Lanka - GOSL. (1991). The Constitution of the Democratic Socialist Republic of Sri Lanka. Sri Jayewardenepura: Parliament Secretariat. 1991.

Italian Librarians Association (ILA). (1997). - The Librarians' Code of Conduct: Fundamental Principles Naples: Italian Library Association.

Mintz, S. M. (1992). Cases in accounting ethics and professionalism. New York: McGraw-Hill. 
Professional Codes of Ethics for Librarians. http://www.ifla.org/en/node/623. Accessed 05.05.2009.

Sri Lanka Library Association (1998). Code of professional conduct and ethics. Colombo: SLLA.

Sri Lanka Library Association (Incorporation) (Amendment) Act no. 7 of 2004. http://www.slla.org.lk/act/slla_act2004.pdf. Accessed May 2009.

Williams, J. R. (2005). World Medical Association - Medical Ethics Manual. Ferney-Voltair Cedex: The WorldMedical Association Inc. 